\title{
Floods in a warmer world: Insights from paleohydrology
}

\author{
Juan Antonio Ballesteros Canovas', L. Schulte ${ }^{2}$, J.P. Corella ${ }^{3}$ and B. Wilhelm ${ }^{3}$
}

\section{Geneva, Switzerland, 11-13 November 2019}

The second phase of PAGES' Floods Working Group (FWG; pastglobalchanges. org/floods) started in January 2019 and will run for three years. The main goal of this second phase is to develop the core activities jointly identified during the first phase (Wilhelm et al. 2017). This workshop in Geneva (pastglobalchanges.org/ calendar/2019/127-pages/1943) allowed us to discuss and advance towards the realization of these objectives. Thirty-two researchers from 12 countries attended, of which more than $30 \%$ were early-career scientists. The workshop also benefited from contributions by Dr. Karen Sudmeier-Rieux, representative of the United Nations Environment Program, and Dr. Marie-France Loutre, Executive Director of PAGES.

The workshop was divided into two sessions. The aim of the first session was to discuss a range of methodologies that integrate multiple natural and historical archives to provide comprehensive paleoflood records for Disaster Risk Reduction (DRR) schemes, while the second session was mostly dedicated to discussing the occurrence and magnitude of floods during past warm and cold periods.

During the first session, the benefits of paleoflood information in DRR schemes were shown throughout different examples. A particular focus has been placed on the dimensioning of key infrastructures such as spillways in hydropower dams, or flood hazard assessments in regions with scarce instrumental data. The workshop participants agreed that advances in the inclusion of historical and paleoflood records in flood hazard assessment were achieved during recent years as well as in its incorporation to derive flood frequency (England et al. 2018). Participants also highlighted that to improve the applicability of paleofloods in DRR, the engagement of stakeholders is crucial.

Participants concluded that an integrated methodological and multidisciplinary approach is imperative to improve the potential replicability of paleofloods research worldwide. This effort, initiated during the FWG session at the PAGES Open Science Meeting 2017 in Zaragoza, is also documented by the 18 research papers compiled in the Special Issue "Pluridisciplinary analysis and multi-archive reconstruction of paleofloods", which was published in the journal Global and Planetary Change (Schulte et al. 2019)

In addition, we noted the importance of enhancing the communication between paleohydrologists, hydrologists, flood engineers, and decision-makers is essential to anticipate impacts of floods. In particular participants discussed the possibility of developing an interdisciplinary audiovisual project as a way to transmit the benefits of including paleofloods in DRR to a broader community. At the same time, participants have started to collect ideas for writing a joint paper on paleofloods and DRR.

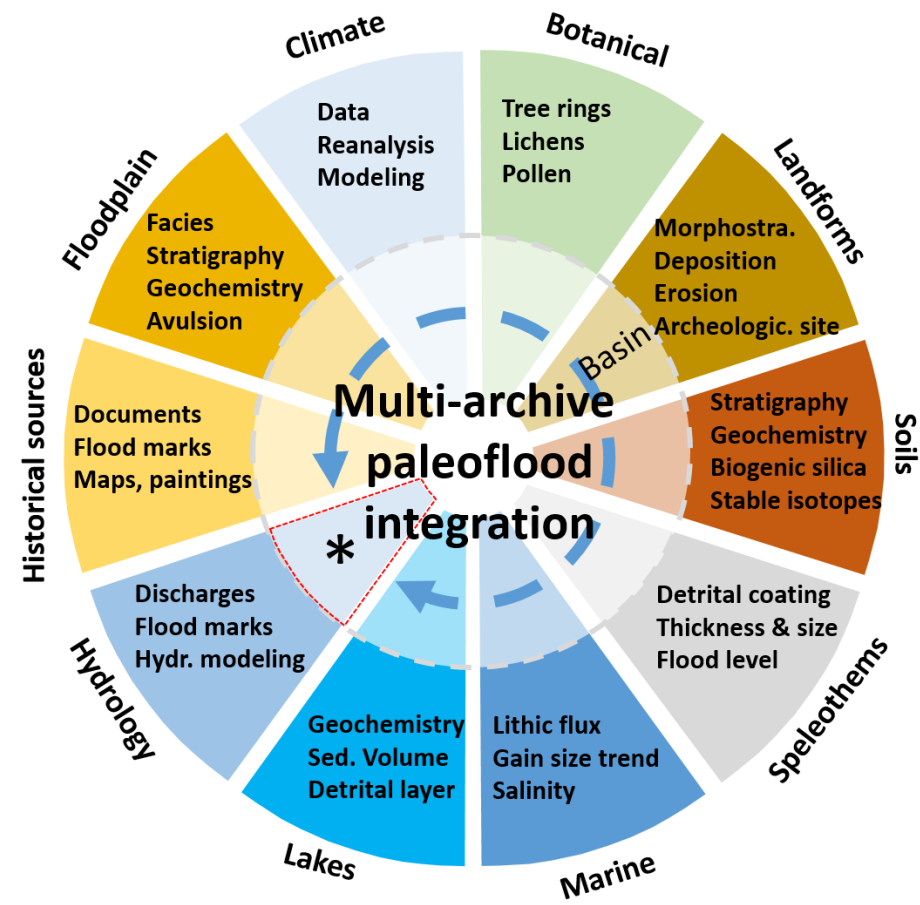

Figure 1: Concept of multi-archive paleoflood integration (in colored slices) according to the type of flood archive (e.g. climate, botanical) for obtaining long-term flood records useful for flood risk preparedness and mitigation $\left({ }^{*}\right)$. Adapted from Schulte et al. (2019).
During the second session, several reconstructions of past flood activity during cold and warm periods were shown worldwide. The workshop attendees discussed the importance of establishing the relationship between changes in the atmospheric variability and flood occurrence. Time-space analysis of regional flood-rich and flood-poor periods allows us to anticipate future changes through our understanding of the forces that control flood occurrence. According to the different methodological approaches and regional studies presented at the workshop, which mostly covered the last centuries,

higher flood activity in many catchments was linked not only to warmer periods but also to colder climate pulses. Yet, flood magnitude and timing evolved differently in different records and regions.

Participants recognized that developing the global database could be challenging due to difficulties in data integration from different archives and the significant amount of time required for this project. However, we came to a consensus that completing the interactive database of metadata of existing records remains a priority (pastglobalchanges. org/science/wg/floods/wp1/data).

Finally, different upcoming FWG-related activities were presented, such as the 6th International Paleoflood Conference in New Zealand (January 2020); a FWG-related session at the EGU General Assembly (3-8 May 2020); and the possibility to organize the 7th International Paleoflood Conference in Zamora, Spain (2022). More information about the workshop, upcoming projects and activities is available on the FWG website.

\section{ACKNOWLEDGEMENTS}

We thank PAGES and the section of Earth and Environmental Science of University of Geneva for the financial support, as well as Alejandra Jimenez, Clara Rodriguez, Alberto Muñoz, and Victorine Castex for their support during this workshop.

\section{AFFILIATIONS}

Department of Earth Science, University of Geneva, Switzerland

2Department of Geography, University of Barcelona, Spain

Univ. Grenoble Alpes, CNRS, IRD, Grenoble-INP, IGE, France

\section{CONTACT}

Juan Ballesteros: Juan.Ballesteros@unige.ch

\section{REFERENCES}

England JF et al. (2018) Guidelines for Determining Flood

Flow Frequency, Bulletin 17C (ver. 1.1, May 2019).

USGS, Virginia, USA, $168 \mathrm{pp}$

Schulte L et al. (2019) Glob Planet Change 177: 225-238

Wilhelm B et al. (2017) White Paper: For an improvement of our flood knowledge through paleodata. PAGES, Switzerland, $15 \mathrm{pp}$ 